\title{
Reviewing the Pitfalls Associated with Centralized Tracking of Students Learning Progress in Large Institutions of Higher Learning
}

\author{
Dr P Muhuro \\ Teaching and Learning Centre, \\ *University of Fort Hare, Private Bag X1314, Alice 5700, South Africa. Email:pmuhuro@ufh.ac.za \\ Prof SM Kang'ethe \\ *Department of social work \\ Prof S.W. Rembe \\ *Department of Further and Continuing Education
}

\section{Doi:10.5901/mjss.2014.v5n11p139}

\section{Abstract}

Incontrovertibly, student tracking and monitoring is a noble strategy to gauge milestones of educational endevours, especially in higher education where diverse students have to be supported. To this end, some institutions have resorted to the use of centralized tracking and monitoring of students' progress in a bid to improve the individualized, targeted outreach and intervention by various professionals. However, the benefits of the centralized and multi-disciplinary approach are not visible, as many still drop out, take too long to complete their programs and show many signs of disengagement. This concern prompted conducting a desktop study to explore pitfalls associated with the delivery of centralised student tracking and monitoring programs in large poorly resourced, higher education settings, with the hope of coming up with possible solutions. The review noted that tracking in large institutions sometimes lack a comprehensive strategy with proper co-ordination and communication to support the diverse students. Specifically poor feedback loop make it difficult to obtain full acceptance by all staff, hence this cripples decision making and planning of alternative strategies. Perhaps tracking could be improved by improving goodwill among the different institutional leaders. Also improved funding of tracking and monitoring initiatives may curb resource shortages which sometimes retard the tracking process. It is especially important to improve the professional capacity of staff involved in intervention.

Keywords: Pitfalls, centralized student tracking, alert support agents, monitoring learning progress, institutions of higher learning.

\section{Introduction and Background to the Study}

Students tracking and monitoring is an integral component of formatively and continuously assessing students' progress in their education endeavours. Tracking is an education process that entails monitoring of learning progress on a specific aspect and devising appropriate interventions. The aspects used as indictors of performance vary across context and may include class attendance, social behavior, psychological wellbeing and academic performance (Hudson, 2005, Ewell, 1995). The processes such as identifying the student at risk indicators, initiating contact and devising an intervention form the core of the program. In the education sector, tracking is an important determinant of the milestones achieved in the implementation of the set educational goals. It is also a way of showing concern for students, particularly those who do not seek support on their own volition (Simons, 2011).

Due to the policy of open access where students of various backgrounds have been allowed access to higher education irrespective of race, gender, tribe or socio-economic standing, (UNESCO, 1998), there has been an unprecedented growth in students' needs. This puts most of the student support administrators at crossroads in terms of finding best ways to meeting these diverse needs.

Undoubtedly, tracking and monitoring of students' progress is regarded as one of the high impact student retention initiatives for disadvantaged students (Kinzie, Gonyea,Shoup \& Kuh, 2008). This is because its outreach approach and use of intrusive methods which make it easier to reach those students who may fall through the cracks (Siedman, 2005, Cuseo, 2006). However, the success of tracking and monitoring lies in ensuring that all the necessary processes are 
effectuated diligently. In fact, a good tracking and monitoring program entails serious planning and heavy capital outlay in terms of resource investment, whether human resource or financial resources (Cuseo, 2006). On the human resource side, professional expertise in the conceptualization of the program as well as mobilizing support are pivotal, particularly for the support agents spearheading the tracking and monitoring program (Jones, Coetzee, Bailey, \& Wickham, 2008). In terms of infrastructure, heavy investment may be needed for the initial set up of a computerized system in order to speed up the identification and outreach processes. Sadly however tracking and monitoring processes may take an add-on approach and have a narrow focus. For instance the student identification activities ought to be effectuated from various institutional community staff so as to address students' needs holistically (Mazza \& Botturi, 2007; Krause, 2005). Still, some monitoring programs heavily rely on academic staff for the process on identification and referral, and this therefore limits the identification of performance indicators to solely academic issues.

There are several approaches or models to implementing tracking and monitoring programs. According to Cuseo (2006), institutions select a tracking and model that align to their unique characteristics and resources. Three main models are centralized, decentralized and mixed model (Simons, 2011). In a centralised model, a team of diverse professionals spearhead the tracking and monitoring processes. In this vein, this model requires a lot of co-ordination and commitment from all those who form the core of the program so that there is clear understanding of the program goals and processes. This increases acceptance from other stakeholders who usually require a lot of awareness campaigns' for them to commit to the program goals. Regrettably, Tinto (2013) noted the lack of coherent goals and intention hinder efforts for effective retention practices.

On another angle, a decentralized model entail individuals taking the responsibility of all the processes such as identifying the student at risk indicators, initiating contact and devising an intervention. Decentralised models are ideal in course based tracking and monitoring programs where the staff member use Learning Management Systems to aid the identification and communication processes ( Mazza \& Botturi, 2007,Simons, 2011). Decentralised models can be effective in small and well-resourced institutions (Fletcher, 2012). However, the decentralized model may fail if staff handle a large number of students as they may get overwhelmed with the work required for program success. The challenge comes at the moment of counseling and intrusive advising of students and devising appropriate interventions. Most importantly visionary leadership to spearhead the process is critical to ensure buy in. Jones et al. (2008) report that institutional leaders are instrumental in ensuring that there is a shared understanding of the institutional goals.

In South Africa, poor performance and low retention among the formerly disadvantaged social groups in higher education is a cause for concern (Scott, Yeld \& Hendry, 2007; DOE 1997). Scott(2009) contends that the higher education system is failing its mandate because the high intake of diverse students is not tallying with desirable results performance and retention. In tandem with this view, John (2013) argues that this high dropout is a result of poor support. Yet the national policies put emphasis on the need to acknowledge the diverse students' needs and support them (CHE, 2012). Many programs have been set up in higher education institutions in a bid to provide support students learning and success. However, there still seem to be limited evidence of the positive outcomes of these programs since student academic performance remains very low, particularly in the first year of study (OECD, 2008). Against this background, the study seeks to find out challenges in the implementation of student support initiatives, particularly challenges associated with monitoring students learning progress in the higher education institutions.

\section{Problem Statement}

In South Africa in particular, so many fingers are being pointed at public higher education because of poor performance in its task of supporting students (Scott , 2009). This is because of poor retention associated with many students from formerly disadvantaged backgrounds ( Lemmens, 2010). This point to the fact that the educational processes at all levels may be lacking tracking. Ewell (1995) believe that if educational processes are adequately tracked, this would give an opportunity for the respective institutions and the government to realize the cracks in the system, and therefore restructure, reformulate or overthrow some of the discrepant practices altogether. This justifies the need for a desktop review to find out the pitfalls associated with the implementation of current tracking and monitoring programs in public higher educational institutions.

\section{Pitfalls Associated with Tracking Learners' Progress in Institutions of Higher Learning}

\subsection{Narrow selection criteria of tracking parameters}

Perceptibly, narrow selection of criteria is hypothesized to impede tracking process. On the aspect of the criteria to 
effectuate tracking and monitoring of students, it is important that various indicators be used (Bashford, 2008 Thompson, \& Geren,2002). To this end, Fusch (2012) concedes that a good tracking system captures student participation in social, psychological and academic activities that impede academic success. In this regard, Ewell et al., (1995) stress the important of keeping an accurate comprehensive record of student participation in various institutional activities such as extra mural activities, health issues, student societies, study groups, advising, counseling, library usage and participation in class activities. This use of multiple indicators adheres to Gardiner's (1987) theory of multiple intelligences asserting that learning takes place through various spaces and media. In the same vein, Kolb (1984) advocates for ensuring that the curriculum delivery, including assessment and monitoring of students' progress take into account the various intelligences and learning styles. Regrettably, in an empirical study of monitoring programs in two year higher education institutions in the United States, Fletcher (2012) found over reliance on academic performance as monitoring indicator. In this vein disadvantaged students particularly require that various indicators be used in order to facilitate their success. (Jones, Coetzee, Bailey, Wickham, 2008). It is also important that tracking and monitoring be appropriately timed.

\subsection{Inappropriate timing of tracking}

Appropriate timing of student tracking and monitoring is critical for the institutional managers to reap the benefits of the program (Siedman, 2005; Madiny, 2005) Since most students make critical decisions about their future during the first three weeks of the first year (Tinto, 1993; Kuh, Kinzie, Schuh, and Whitt, 2005b), this is an ideal time to implement tracking so as to support students in realizing their goals (Pascarella \& Terrenzini, 2005). The pitfall, however, is that in some cases, student tracking may be dragged longer and this makes it difficult for staff to implement sufficient interventions that produce the anticipated results. Most importantly, there is need for adequate resources in terms of infrastructure and human resources.

\subsection{Inadequate personnel/ infrastructure to widen the scope of tracking}

Undeniably, tracking of students' progress in any institution requires a heavy capital outlay. Observably, tracking and monitoring programs reap high rewards or outcomes if there are robust electronic infrastructures so that the process of identifying students' needs and communicating them among the various stakeholders is expedited (Lamp \& Rice, 2008). With regards to infrastructure, student tracking and monitoring programs make use of computer hardware and software infrastructures that sometimes have to be imported from oversees. To this end, Naidu (2002) observed that in South Africa, import duties make it very expensive for some higher education institutions to afford the necessary infrastructure. The institutional budgetary constraints may affect the construction and maintenance of rebuts ICT infrastructure (Heeks, 1999). This in turn limits speedy tracking and monitoring of students learning progress.

Furthermore, staff to run, manage, and effectuate tracking require technical skills to specify relevant indicators for tracking students, as well as to interpret the information that is extracted by the computer system. However, Johnson et al., (2006) found that adoption of technological tools for teaching and learning are hampered by lack of training and expertise. Observably and realistically, the absence of the requisite skills among the staffs hampers tracking program outcomes. In some instances, there is a shortage of such qualified professionals due to difficulties in the recruitment process. This is because the caliber of staff required to competently effectuate tracking is usually targeted by corporate bodies (Kengwe, 2003;Muhuro, 2008).

\subsection{Students ignore calls for counselling on their progress}

One of the other pitfalls associated with tracking are students' negative attitudes and negative perceptions of the role of counseling. Oftenly, many potential risk factors do not readily respond to outreach made by tracking support staff such as advisors and counselor. Given that both counselling and advising role greatly rely on students willingness to be helped (Williams, 2007; Shinn, 2009), this has often rendered tracking and the need to help students an arduous and an uphill task. While student tracking and monitoring is aimed at supporting those students who show indicators of risk, it appears as if psychological factors greatly contribute to the negative responses. This is because apparently at times students feel inadequate the moment they realize that they are not performing up to expectations. For instance some students associate tracking with deficiency. Such kind of students may feel inadequate, stigmatized by being on the spot of having failed to accomplish their learning goals (Lau, 2003). These negative emotions associated with unacceptable performance is the main reason for student resistance to contact staff (Nicholas, 2002; Modipane, 2011). Such students can be vulnerable, aggressive, develop low self esteem, experience depression and anxiety ( Venit, 2008, 2010). 
Research shows that not all students respond immediately to face-to-face contact with the advisor (Govalias et al., 2010; Venit, 2008; Longden, 2004 ). In fact, other studies show that some helping professionals may require up to four communication attempts using various modes to persuade the student to make the initial contact (Nicholas, Damianova \&, Ntantiso, 2011; Govalias, 2008;Fethham, 2006). The glaring challenge at this juncture is how the university enforce interventions if students fail to head calls for counselling.

However, it is good to try to locate the sources or factors that underpin poor performance of the students. Some researchers hypothesize that some students can be detected to be potentially at risk due to poor culture of learning or use of inappropriate learning strategies (Entwistle, 1996). Thus it is important that effective classroom strategies be used to enhance student learning (Ginsberg, Wlodkowski, 2000).

\subsection{Poor Coordination Due to Inadequate Staffing And Poor Infrastructure}

Tinto $(2008 ; 2013)$ contends that coherent goals and intention in student retention is important so as not to frustrate the effort for institutional retention practices. In tandem with this view, Cuseo (2006) asserts that a clear plan of action with respect to student tracking is necessary so that all the stakeholders are aware of the rationale for the program. In this vein, Jones et al., (2008) report that institutional leaders are instrumental in ensuring that there is a shared understanding of institutional goals. These visionary goals should be championed by capable individuals with requisite skills and experience to mobilise others to accept the plan through awareness strategies, marketing and shared decision making. This requires effective coordination. Otherwise, the plans are likely to fail if there is inadequate consultations and coordination among the tracking management stakeholders. If other support staff have not embraced tracking, have not been asked about it, or do not know the policy, it would be difficult to expect the program to succeed. Apparently, the reason why most of the educational innovations fail is the limited consultations of the innovation to all the stakeholders. Consultative participation of all stakeholders make it possible to create a sense of ownership of the program.

\section{Way Forward}

Perhaps tracking and monitoring of students in large institutions could be improved by ensuring that the lecturers also take part in the outreach. This aligns to the view that staff who have frequent contact with students are likely to have developed more rapport with students than tracking support staff, hence likely to be respected. Also, strategies for dealing with at risk students can be infused in the curriculum ( Thomson \& Geren, 2002, Taylor, 2005). Furthermore the responsibility for tracking students must be seen as everyone's responsibility rather than confining it to a few individuals/tracking officials. These researchers think that involving as many individuals as possible in the tracking continuum could be pivotal and instrumental in diminishing aspects of students' risks as much as is possible. This is because although tracking officials are the bonafide personality to perform the task, the principle of comparative advantage places the role of the academics as rich individuals in addressing the students' risks. Some may have more appealing rapport that could be a plus in the continuum of tracking dispensation. Therefore, the goodwill of a multidisciplinary team in the tracking fray could be central to annihilating students' risks, or reducing them to a manageable level. Also, improved funding of tracking and monitoring initiatives may curb resource shortages which sometimes retard the tracking process. It is especially important to improve the computerized tracking processes as well as increase number of professionals dealing with tracking. Most importantly professional development on best practice in the program implementation is also critical for program success.

\section{Conclusion}

This desktop study explored pitfalls associated with the implementation of tracking and monitoring programs in public institutions of higher learning. This was prompted by the observation that the existence of centralized and multi disciplinary approach to student tracking was not always producing visible positive results. The assumption was that large poorly resourced, higher education settings might have unique dynamics which needed to be addressed if tracking and monitoring programs are to achieve positive results. The review noted that tracking in large institutions sometimes lack a comprehensive strategy. Specifically, late initiation of the tracking process diminishes the time for interventions. Perhaps basing tracking on historical data could improve program outcomes. Also students negative perceptions about student tracking and monitoring program result in low response to outreach. This is usually evidenced by poor response to calls for advisory services. While students' attributes also contribute to the urgency of response, other times poor co-ordination and communication among the different sections dealing with student support contributed to poor program success. 
Specifically poor feedback loop make it difficult to obtain full acceptance by all staff, hence this cripples decision making and planning of alternative strategies.

\section{References}

Astin, A. (1993). What Matters in College. Four critical areas revisited. San Francisco: Jossey Bass.

Bashford, J. (2008). Using student Data from an insitutional perspectives. New Directions for Community Colleges , 143, 31-36.

Bojuwoye, O. (2002). Stressful Experience of First year students in selcete duniveristies in South Africa. Counselling Psychology , 277290.

Borden, V. (1995). Harnessing New Technologies for student tracking . New Directions for institutional research , 87, 55-65..

Chickering, A.W. \& Gamson,Z.F. (1987). Applying the Principles of Good teaching in undergraduate education. San Francisco: Jossey Bass.

Chireshe,R. (2012). Carreer Guidance and Counselling Provision at a South African University. Anthropologist. , 14 (4), 305-310.

Cuban, L. (2003). Oeversold and undersused computers in the classroom. Cambridge: Open Univeristy Press.

David, Prince., \& Jenkins Paul,D. (2005). Building pathways to success for low skill community college: Policy and practice of tracking students. Columbia University. New York: Community College Research Centre.

Du Plessis, S. (2005, September 26-27). Cracking the tracking code:Creating a Tracking system that supports teaching and learning. Cape Town, Western Cape, South Africa: Tracking and Monitoring Workshop organised by the Council on higher Education.

Ewell, P. (1995). Student tracking: New techniques, new demands. San Francisco: Jossey Bass.

Fletcher, D. (2012). A National study of early alert programs at two year insitutions of higher education. Arkansas University:. Proquest

Fusch, D.(2012, Dec 7). At risk students. What data are you looking at Academic impressions, 1-15.

Ginsberg, M.B., Wlodkowski, R.J. (2000). Creating highly motivating classrooms for all students: A schoolwide approach to powerful teaching with diverse students (1st ed ed.). San Francisco: Jossey-Bass.

Giovazolias, M.J., Leontopoulou, S \&Trivia,S. (2010). Assessment of Greek students counselling needs and attitudes. International Journal for the Advancement of Counselling , 32, 101-116.

Hartung, D. (2009). Unity and Relevance.envisioning Career Counselling in future Higher Educuation. South African Journal of Higher Education 23 (3), 459-468.

Heeks, D.(1999). Information and Communication Technologies in Developing Countries. Failures, Successes and Local improvisations. The information society, 28(3),101-112

Hudson,W. (2005). Can Early Alert Excessive absenteesm warnign system be effective in retaininf freshmen . Journal of College student retention, Research,, theory and Practice, 7 (3/4), 217-226.

Jones, B., Coetzee, G., Bailey, S, \& Wickham, S.(2008). Factors that facilitate success of disadvantaged higher education students: an investigation into approaches used by REAP, NSFAS and selected higher education institutions. Atholone. Rural Development Access Programme.

Kengwe, J.(2003). Faculty integration of technology into instruction and students knowledge of computer technology to improve students leanring. Journal of Information Technology (JITE) (6), 169-180.

Kolb, (1969).

Kuh, G. D., Kinzie, J., Schuh, J. H., and Whitt, E. J. (2005b). Creating conditions that matter. San Francisco: Jossey-Bass.

Kinzie.,J., Gonyea.,R.,Shoup., Kuh, GD. (2008). Promoting Persistence and Success on underepresented Students: Lessons for Teaching and Learning. New Directions in Higher Education , 23-34.

Kuh, G. (2007b). What college student data tell us about student readiness. AACU Peer Review , 9 (1), 4-8.

Lamp, S., \& Rice, S. (2008). Effective Intervention Strategies For at Risk Students Early Leaving . Discussion Paper. University of Melborne. Melbourne: Centre for Post Secondary Education and Lifelong Learning.

Luke II, C.L (2009). An examination of the psychology underlying successful retention practices. Doctoral thesis. University of Tennesse.

Lau, L. (2003). Institutional factors affecting student retention. Education , 126-136.

Lemmens, J. (2010). Students readiness for university education. University of Pretoria. Pretoria: Unpublished doctoral thesis.

Muhuro, P. (2008). An investigation into the availability ad use of Information and Communication techinlogies at an African University, Masters thesis. University of Fort Hare.

Modipane, M. (2011). Initial experiences of first entering students at the University of Limpopo: Implications for coping with studies. South African Journal on Higher Education , 25 (8), 1592-1607.

Naidu, S.( 2002). Learning and Teaching with technology. Kogan Page.

Nicholas, L.,Daminova, M \& Ntantiso, M. (2011). A comparison of South African and international Counselling needs and prefrred sournces. Australian Journal of Guidance and Counselling , 23 (1), 106-115.

Nimmons, F. (2003). Rationale for tracking: Tracking pupils' progress. Primary Science Review, 80, 2-15.

Pascarella, E. Terrenzini,P. (2005). How College Affects Students: A third decade of insitutional research ( Vol II). San Francisco: Jossey-Bass Higher and Adult Education.

Scott, I., Yield, N., Hendry, J. (2007). (2007). A Case for Improving Teaching and Learning in South African Higher Education. Centre for Higher Education Development. Pretoria: Council on Higher Education .

Shinn, M. (2009). Identifying students at risk, monitoring performance and determining eligibility within response to intervention. School psychology review, 36 (4), 601-617. 
Siedman, A. (2005). College Student Retention: Formula for Success. Westport CT: Praeger.

Simmons. (2011). A National study of early alert models at four year insitutions of higher education. Doctoral Thesis. Universiry of Arkansas. Proquest Dissertations and Thesis

Singell,L.D. \& Wadell,G.R. (2010). Modelling retention at a large public university : Can at risk students be identified early enough to be treated. Research in Higher Education .

Tait, H., Entwistle,N. (1996). Identifying students at risk through study strategies. Higher Education, 97-116.

Taylor, R. (2005). Creating a connection:Student retention through curriculum development. Journal of Further and Higher Education , 29 (4), 367-374.

Thompson, B.R.\& Geren, P.R. (2002). Classroom Strategies for identifying and helping students at risk of Academic Failure at College. Student College Journal , 36 (2).

Tinto, V. (1993). Leaving College. Rethinking the causes and cures of student attrition. Chicago(Ed). Chicago Univarsity Press.

Tinto, V. (2005). Reflections on retention and persistence : institutional actions on behalf of student persistence. Studies in Learning, Evaluation, Innovation and Development, 2 (3), 9-97.

Umbarch, P. P. (2002). Faculty Matter: Role of Faculty in student learning and engagement. Research in Higher Education , 43, 209234.

UNESCO. (1998). World Declaration on higher education for the 21st century: Vision and Action. Paris: United Nations Educational, Scientific and Cultural Organisation.

Venit, E. P. (2008). Student Retention Strategies at Midsize Public Universities. University Leadership Council. Washington: Advisory Board Company.

Williams, S. (2007). From Theory to Practice: The Application of theories of Development to Acadmeic Advising philosophy and practice. (NACADA, Editor) Retrieved 10 17, 2013, from http://www.nacada.ksu.edu/Resources/Clearinghouse/View-Articles/Applying Theory-to-Advising-Practice.aspx

Yorke, M. L. (2004). Retention and student success in HE. Mandehead SRHE and Open University Press. 